\title{
Um relato de si: a trajetória de Carolina Maria de Jesus através dos diários
}

\author{
Leidiana da Silva Lima Freitas* \\ Maria Suely de Oliveira Lopes ${ }^{* *}$
}

Resumo: Neste artigo propomos analisar a escrita de si de Carolina de Jesus a partir de seus diários: Quarto de Despejo (2014a), Casa de Alvenaria (1961) e Diário de Bitita (2014b). Especificamente, buscamos entender a trajetória de vida da escritora através de seus diários, além de traçarmos uma linha comparativa entre eles. Sob nossa análise, compreendemos que esses escritos não se constituem como simples relatos da vida da escritora, mas, sobretudo, como armas utilizadas por ela para denunciar a miséria, o racismo e o preconceito vividos por grande parte da população do Brasil.

Palavras-chaves: Escrita de si. Diários. Trajetória. Carolina Maria de Jesus.

Abstract: In this article we propose to analyze the self-writing of Carolina de Jesus from her diaries: Quarto de Despejo (2014), Casa de Alvenaria (1961) and Diário de Bitita (2014b). Specifically, we seek to understand the life trajectory of the writer through her diaries; in addition to drawing a comparative line between them. Under our analysis, we understand that these writings do not constitute mere accounts of the writer's life, but, above all, as weapons used by her to denounce the misery, racism and prejudice experienced by a large part of the population of Brazil.

Keywords: Self-writing. Diaries. Trajectory. Carolina Maria de Jesus.

Resumen: En este artículo proponemos analizar escrita de sí de Carolina de Jesús a partir de sus diarios: Quarto de Despejo (2014a), Casa de Alvenaria (1961) y Diário de Bitita (2014b). Específicamente, buscamos entender la trayectoria de vida de la escritora a través de sus diarios; además de trazar uma línea comparativa entre ellos. Bajo nuestro análisis, comprendemos que estos escritos no se constituyen como simples relatos de la vida de la escritora, sino, sobre todo, como armas utilizadas por ella para denunciar la miseria, el racismo y el prejuicio vividos por la mayoría de la población de Brasil.

Palabras clave: Escritura de sí. Diarios. Trayectoria. Carolina María de Jesús.

\footnotetext{
* Mestranda em Letras pela Universidade Estadual do Piauí. Técnica em Assuntos Educacionais no Instituto Federal do Piauí. Professora da Secretaria Estadual de Educação do Piauí. http://orcid.org/oooo0002-9568-1974

** Professora Adjunta da Universidade Estadual do Piauí (UESPI) e membro do Grupo de Estudos Interdisciplinares em Literatura (INTERLIT) e filiada à ADHILAC. http://orcid.org/oooo-0003-1036-4986
}

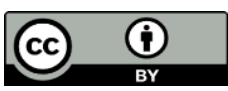




\section{Considerações iniciais}

Carolina Maria de Jesus é uma escritora fora dos padrões. Negra, pobre e semianalfabeta, ela desafia os parâmetros estabelecidos por uma época, ao se apresentar como autora.

A sua ousadia ao se mostrar para o jornalista Audálio Dantas, em 1958, possibilitou-lhe a publicação de seu primeiro livro, em 1960, escrito em formato de diário: Quarto de Despejo: diário de uma favelada, por meio do qual Carolina de Jesus retrata a vida na favela do Canindé, além da miséria e da fome das pessoas que habitavam aquele lugar.

A publicação do primeiro diário rendeu-lhe fama, visto que ela se tornou conhecida no mundo inteiro, além de dinheiro, o que a permitiu sair da favela e alcançar o grande sonho de viver em uma casa de alvenaria.

Em 1961, ela publica Casa de Alvenaria: diário de uma ex-favelada. Agora, na sala de visitas, Carolina de Jesus continua escrevendo seus diários, porém, a partir de uma nova perspectiva. Os principais relatos, nesse diário, giram em torno da assinatura do contrato para publicação de Quarto de Despejo, das visitas às livrarias, entrevistas aos jornais e às televisões, da saída da favela e da conquista de sua casa.

Em 1986, é lançado no Brasil outro diário da escritora: Diário de Bitita. Esse livro, lançado primeiramente na França em 1982, traz as lembranças da infância e da adolescência da escritora. O preconceito e a pobreza são temas acentuados nas narrativas de Bitita, nome pelo qual Carolina de Jesus gostava de ser chamada quando criança.

Nesse sentido, vale destacar que o gênero diário é bastante comum, principalmente no meio feminino. Isso se justifica pelo fato de que as mulheres, no passado, não eram aceitas como escritoras, não podiam escrever para o público, e utilizavam a prática da escrita em diário como meio de registrar seus pensamentos, angústias e desabafos. Nessa perspectiva, Perrot (2007) defende que gêneros como correspondência, diário íntimo e autobiografia não são especificamente femininos, mas 
tornam-se mais adequados às mulheres em virtude do seu caráter privado. Embora Carolina de Jesus tenha ganhado evidência através da publicação de seus diários, a autora também escreveu romance, poesia, peças teatrais, letras de sambas, entre outros.

Diante dessas informações, neste artigo propomos analisar a escrita de si de Carolina Maria de Jesus, a partir de seus diários. De forma específica, buscamos entender a trajetória de vida da escritora através de seus três diários, além de traçarmos uma linha comparativa entre eles. O primeiro diário a ser publicado foi Quarto de Despejo (2014a), em seguida, Casa de Alvenaria (1961) e Diário de Bitita (2014b). Para atingir os objetivos propostos, contamos com os aportes teóricos de Foucault (2011), Butler (2015), Fernandez (2019), entre outros que subsidiaram esta pesquisa.

\section{Um relato de si em forma de diários}

Carolina Maria de Jesus é uma escritora negra, semianalfabeta e favelada que ganhou destaque no Brasil e no exterior ao publicar o livro Quarto de Despejo: diário de uma favelada, em 1960. O referido livro está organizado em formato de diário, no qual Carolina de Jesus retrata a vida de pobreza, a miséria na favela do Canindé e a luta diária para prover o sustento dos filhos.

Além do livro citado, outros dois diários da escritora também foram publicados: Casa de Alvenaria: diário de uma ex-favelada, em 1961 e Diário de Bitita, em 1986. Enquanto neste relembra fatos da sua infância e da adolescência; naquele, ela escreve sobre as mudanças que ocorreram em sua vida com a publicação do seu primeiro diário, em 1960.

Através de seus escritos, Carolina de Jesus critica, denuncia e questiona a situação de miséria e de preconceito enfrentados pelos negros e pelos pobres, especialmente, em Quarto de Despejo (2014a) e Diário de Bitita (2014b), tendo em vista que em Casa de alvenaria (1961), a narradora centra a sua narrativa nas conquistas decorrentes da publicação de seu primeiro livro.

Escrever sobre si não é algo novo. O diário é um gênero textual bastante comum, especialmente no meio feminino. De acordo com Joviano (2011), uma das características 
básica de um diário é o relato do cotidiano, além da narração ser centrada em fatos vividos.

Embora o diário já tenha sido considerado um gênero menor, destinado às mulheres, ele tem papel significativo, porque permite a expressão da subjetividade feminina. Para Perrot,

O diário ocupa um momento limitado, mas intenso, na vida de uma mulher, interrompido pelo casamento e pela perda do espaço íntimo. Está ligado ao quarto das meninas. Por um breve tempo permite a expressão pessoal. Esses diversos tipos de escritos são infinitamente preciosos porque autorizam a afirmação de um "eu". E graças a eles que se ouve o "eu", a voz das mulheres. Voz em tom menor, mas de mulheres cultas, ou, pelo menos, que têm acesso à escrita. E cujos papéis, além do mais, foram conservados. São condições difíceis de ser cumpridas. (PERROT, 2007, p. 30, grifo da autora)

Na perspectiva de Perrot (2007), os diários são importantes, uma vez que possibilitam às mulheres romperem com a barreira do silêncio. Conforme defende a autora, muito tem se falado sobre a mulher, mas faz-se necessário que a própria mulher fale de si, da sua vida, das suas angústias, de seus desejos e nesse ponto, o diário foi um instrumento significativo para as mulheres.

Embora Carolina de Jesus tenha recebido pouca instrução escolar, a autora lia tudo o que encontrava, aperfeiçoando assim a sua escrita, especialmente por meio de seus diários. Esses permitiam à escritora externar suas vivências e experiências, suas angústias e suas alegrias.

Para Butler (2015, p. 30), o relato de si nunca carrega uma totalidade do que foi vivido pelo narrador, visto que as palavras são "interrompidas pelo tempo de um discurso que não é o mesmo tempo da minha vida”. Dessa forma, embora os diários de Carolina de Jesus sejam autobiográficos, a autora, ao escrever, seleciona e recorta as situações as quais quer relatar, dando prioridade a alguns fatos e omitindo outros, pois há sempre algo que não pode ser relatado. Nesse sentido, Butler defende que

Os sujeitos que se narram em primeira pessoa encontram uma dificuldade comum. Há momentos em que claramente não posso contar a história em linha reta, então perco o fio da meada, começo de novo, esqueço um elemento 
crucial, e fica difícil pensar em como introduzi-lo na trama (BUTLER, 2015, p. $55)$.

Relatar a si mesmo é uma tarefa árdua, visto que ao narrar os fatos, necessariamente recorre-se à memória, às lembranças, que não surgem de forma linear. Alguns fatos são enfatizados, outros são esquecidos, sendo necessário, muitas vezes, recomeçar o seu relato.

A escrita de si, na perspectiva de Foucault (2011, p. 130), é uma completude, uma forma de fugir dos perigos da solidão. Para o autor, "o facto de se obrigar a escrever desempenha o papel de um companheiro", tendo em vista que a escrita é um ato solitário, um exercício pessoal.

Inicialmente, Carolina de Jesus escrevia para fugir da miséria e da pobreza, fez da sua escrita um modo de sobrevivência; seus diários eram seus companheiros. Posteriormente, fez-se lida. Além de tirar o sustento a partir da publicação de suas obras, usava-as para denunciar o que a incomodava, as injustiças que via e vivia, postava em seus textos mais que suas vivências, imprimia a sua identidade, a sua marca.

Foucault (2011, p. 144) assevera que "tal como um homem traz no rosto a semelhança natural com os seus antepassados, assim é bom que se possa aperceber naquilo que escreve a filiação dos pensamentos que ficaram gravados na sua alma”. Carolina de Jesus escrevia sobre o que vivenciava, escrevia sobre o que conhecia bem, culminando numa escrita original. Segundo a própria autora, "é preciso conhecer a fome para descrevê-la”' (JESUS, 2014a, p. 29).

A escritora conhecia a fome desde a infância. Os fatos narrados em seus diários não são simples relatos ou frutos da ociosidade, são, principalmente, uma maneira que ela encontrou de mostrar o sofrimento, o preconceito e a pobreza de todos aqueles que vivem em situações semelhantes a que ela viveu. Ademais, esses escritos são a forma que ela encontrou de resistir aos infortúnios pelos quais passou durante sua trajetória.

Nesse sentido, Fernandez defende que,

\footnotetext{
${ }^{1}$ Todos os excertos dos diários, corpus deste artigo, serão transcritos conforme os textos originais.
} 
Carolina de Jesus "ruminava" suas horas, seus passos, suas reflexões e emoções, ao longo do dia, visando pôr tudo em seu diário, uma vez que escreveu seu diário para viver, mais do que para mostrar o que viveu. Escrever suas carências foi a primeira forma de superá-las e compreendê-las; depois, reutilizar pessoas, nomes e assuntos escamoteados em seus experimentos literários. Após sua 'descoberta' e a possibilidade de transformação de seu diário em livro, mais ainda se tornou imperativo escrever e tudo registrar (FERNANDEZ, 2019, p. 267, grifo da autora).

Carolina de Jesus não escrevia só para mostrar seus infortúnios ou registrar tudo que vivia, sentia e a angustiava, mas, sobretudo, escrevia porque foi a maneira que ela encontrou de resistir à miséria e à pobreza. Escrevia porque sua escrita era a única arma da qual dispunha para superar suas dificuldades, quando passou a ganhar algum dinheiro com os seus escritos, entendeu o quão importante era continuar escrevendo para prover o sustento seu e de sua prole.

Através da escrita de si, a autora denuncia as injustiças sociais e luta para transformar sua realidade. Escrevia com o corpo e com a alma, usando a sua escrita como uma arma para superar os desafios impostos pela difícil situação vivenciada por ela desde sua infância. Para Foucault (2011, p. 143, grifo do autor), "a escrita transforma a coisa vista ou ouvida 'em forças e em sangue”'. Era isso que a escrita representava para Carolina de Jesus, sua força, sua arma, seu sangue.

Além de denunciar as injustiças que vivia ou presenciava, a escritora questionavaas com o intuito de entendê-las. Esse desejo de entender as injustiças sofridas pelos negros e pelos pobres, impulsionou Carolina de Jesus a fazer esse relato de si.

Nesse sentido, Butler (2015, p. 13) defende que o relato de si acontece quando há uma interpelação, a partir de um sistema baseado na justiça e no castigo, porém, a autora, esclarece que pode "haver um desejo de conhecer e entender que não seja alimentado pelo desejo de punir, e um desejo de explicar e narrar que não seja propelido pelo terror da punição".

No prefácio do livro A poética de resíduos de Carolina Maria e Jesus, de Raffaella Fernandez, Silva afirma que a escritura de Carolina de Jesus se debruçava sobre sua memória; aparentemente, ela não tinha "um projeto literário maior que o de narrar sua 
vida e o cotidiano que a envolvia, ela tece uma escrita íntima, de si, dos outros, da cidade, do país" (2019, p. 5).

Embora seja uma escrita de si, centrada na primeira pessoa, os escritos de Carolina de Jesus representam a coletividade, tendo em vista que muitos outros passavam e ainda passam pela mesma situação que ela e sua família. Por estar inserida em uma comunidade, seu relato era também o relato desses outros, excluídos e marginalizados.

\section{Quarto de despejo: a vida na favela}

No ano de 1958, Carolina de Jesus, uma mulher negra e pobre que habitava a favela do Canindé chamou a atenção de um jornalista, Audálio Dantas, que realizava entrevistas com o povo naquele recinto. Ousada e com o sonho de tornar-se uma escritora, a moradora apresentou seus escritos ao jornalista, e em 1960 ganhou destaque, tanto no Brasil como no exterior, com o lançamento do seu diário intitulado Quarto de Despejo: diário de uma favelada.

O diário, através do qual a escritora narra seus dias de favelada, logo alcançou sucesso. Segundo Meihy e Levine (2015, p. 30), "No espaço de um ano ela havia se equiparado, em vendagem, a Jorge Amado, e, como ele, se transformado no mais traduzido dos autores brasileiros de todos os tempos”.

No prefácio de Quarto de despejo, datado de 1993, Audálio Dantas afirma que acima da curiosidade dos consumidores "[...] pairava a força do livro, sua importância como depoimento, sua autenticidade e sua paradoxal beleza”. Uma beleza ímpar, visto que Carolina de Jesus conseguiu transformar a fome em poesia.

As páginas de Quarto de Despejo (2014a), para além de um relato pessoal, são o retrato do sofrimento de todos os favelados que compartilhavam das mesmas agruras que a escritora. Perpétua (2014, p. 23) defende que esse diário é "Escrito por quem testemunha a miséria dia após dia e é capaz de torná-la objeto de uma narrativa sob um ângulo novo, o diário apresenta o modo de vida da população excluída socialmente”. 
Em suas narrativas, a autora releva sua impotência diante da pobreza e da fome. Logo no início do diário, mais precisamente no dia 15 de julho de 1955, ela lamenta sua condição: "Aniversário de minha filha Vera Eunice. Eu pretendia comprar um par de sapatos para ela. Mas o custo dos gêneros alimentícios nos impede a realização dos nossos desejos. Atualmente somos escravos do custo de vida” (JESUS, 2014a, p.11).

Nas páginas do referido diário, a fome transforma-se em uma personagem constante, moldando a vida das pessoas da favela do Canindé. A autora, ao longo de sua narrativa, retrata as dificuldades enfrentadas diariamente, como a miséria e a fome, revelando “[...] um ambiente urbano pouco conhecido então - a favela” (PERPÉTUA, 2014, p. 23).

A fome é a grande protagonista e ao mesmo tempo a vilã. Diante dela, o homem desumaniza-se, revira o lixo em busca de comida, como já afirmava Manuel Bandeira (1947) no poema $O$ bicho. Carolina de Jesus retrata essa realidade em algumas passagens de seu diário, situações que presenciou e também viveu, como no trecho em que ela cita: "Eu ontem comi aquele macarrão do lixo com receio de morrer" (JESUS, 2014a, p.39). Duas páginas à frente ela escreve: "Achei um cará no lixo, uma batata-doce e uma batata solsa” (JESUS, 2014a, p.41). A fome obriga o homem a viver dos restos deixados pelos outros, e como animais famintos, nem examinam, apenas devoram o que encontram pela frente.

Outro sentimento que a autora deixa transparecer em seus escritos é a aversão que ela tem à favela. Assim, ela escreve:

\begin{abstract}
As oito e meia da noite eu já estava na favela respirando o odor dos excrementos que mescla com o barro podre. Quando estou na cidade tenho a impressão que estou na sala de visita com seus lustres de cristais, seus tapetes de viludos, almofadas de sitim. E quando estou na favela tenho a impressão que sou um objeto fora de uso, digno de estar num quarto de despejo (JESUS, 2014a, p. 37).
\end{abstract}

Carolina de Jesus deixa claro que não se adéqua à vida na favela. Seu desejo é sair do quarto de despejo e ocupar a sala de visitas, fato bastante citado em seu outro diário, Casa de alvenaria (1961). Conforme a autora, São Paulo era dividido da seguinte maneira: “O Palácio, é a sala de visita. A prefeitura é a sala de jantar e a cidade é o jardim. E a 
favela é o quintal onde jogam os lixos" (JESUS, 2014a, p. 32). Enquanto as pessoas que vivem na sala de visitas usufruem do luxo e da mordomia, as que vivem nas favelas sofrem com as péssimas condições de vida e de higiene.

Apesar de todas as dificuldades enfrentadas, Carolina de Jesus sempre se mostrou uma mulher forte, batalhadora, protetora, solidária e, acima de tudo, sonhadora. Conforme podemos observar no trecho a seguir.

Enquanto escrevo vou pensando que resido num castelo cor de ouro que reluz na luz do sol. Que as janelas são de prata e as luzes de brilhantes. Que a minha vista circula no jardim e eu contemplo as flores de todas as qualidades... É preciso criar este ambiente de fantasia, para esquecer que eu estou na favela (JESUS, 2014a, p.58).

A escrita, nesse sentido, era essencial, prova disso é que em diversas passagens de Quarto de despejo (2014a), ela menciona o ato de escrever, que funciona como uma espécie de válvula de escape. Dessa forma, escrever vai além da expressão dos sentimentos. As páginas dos diários não são apenas registros do seu cotidiano, são a forma encontrada pela escritora para fugir das amarguras e da miséria vivenciada por ela. Através da escrita, ela se transporta para um ambiente paralelo, totalmente oposto à realidade da favela.

O olhar crítico sobre a favela é outro ponto que merece ser ressaltado. Em um dos trechos do diário ela relata,

\footnotetext{
Quando eu vou a cidade tenho a impressão que estou no paraizo. Acho sublime ver aquelas mulheres e crianças tão bem vestidas. Tão diferentes da favela. As casas com seus vasos de flores e cores variadas. Aquelas paisagens há de encantar os olhos dos visitantes de São Paulo, que ignoram que a cidade mais afamada da América do Sul está enferma. Com as suas ulceras. As favelas (JESUS, 2014a, p. 76).
}

Diante do excerto, observamos que a autora elogia a vida na cidade, pois tem o desejo de habitar uma casa de alvenaria. Contudo, ela não esconde os problemas da favela, o outro lado, ignorado, desconhecido e excluído, o quintal onde se joga o lixo, como afirma a própria Carolina de Jesus. 
Associada ao olhar crítico que a escritora lança sobre a favela, há também a crítica feita aos políticos. De acordo com ela, os políticos iludem os eleitores com promessas de que estão do lado do povo, porém, após as eleições, divorciam-se do povo. A autora acreditava que o Brasil deveria ser governado por quem passou fome, tendo em vista que a fome é professora e ensina a pensar no menos favorecido.

Apesar do sucesso estrondoso advindo da publicação desse diário, os demais livros da escritora não tiveram a mesma aceitação, como consequência, “[...] ela foi forçada a voltar à condição de pobre, com dificuldades de sobrevivência. Na miséria, viu terminarem seus dias" (MEIHY; LEVINE, 2015, p. 19). A ascensão que obteve através da publicação de Quarto de Despejo (2014a) não rendeu à Carolina de Jesus o suficiente para livrá-la da pobreza. Conforme os autores mencionados, com a diminuição das rendas dos direitos autorais, ela foi forçada a novamente catar papel e latas para sobreviver e, mesmo vivendo em melhor situação do que na favela, não era o esperado para alguém que vendeu livros em diversos países.

Quarto de Despejo (2014a) é um marco revolucionário por diversas razões: além de retratar as experiências de quem realmente conhecia a miséria, a pobreza e a fome, representa uma denúncia social de uma realidade ignorada pela sociedade. Ademais, esse diário opõe-se aos padrões literários canônicos da época, tornando conhecida mundialmente a mulher, negra, pobre, semianalfabeta e favelada que tirava do lixo o sustento e a inspiração para escrever.

\section{Casa de alvenaria: a vida na sala de visitas}

Em 1961, após o sucesso com a publicação de Quarto de Despejo: diário de uma favelada, Carolina de Jesus publica outro livro: Casa de Alvenaria: diário de uma exfavelada. Diferente do primeiro, que ganhou as graças dos brasileiros e estrangeiros, esse outro diário não teve a mesma repercussão.

Nesse relato, ao contrário do que se observou no primeiro diário da autora, a favela sai de cena. Colhendo os louros do seu trabalho, ela retrata a vida a partir da sala de visitas. Os fatos narrados em Casa de Alvenaria (1961) configuram-se, principalmente, 
em torno da realização do grande sonho da escritora de sair da favela e ter uma moradia para findar seus dias.

Ao longo da narrativa, a autora retoma um aspecto já anunciado em Quarto de Despejo (2014a): o desejo de sair da favela e comprar uma casa ou um sítio. Para concretizar esse sonho, ela conta com o dinheiro recebido com a venda dos exemplares do seu livro. Procurada por um economista que lhe propõe o investimento em um empreendimento, ela responde: "A única coisa que quero é comprar uma casinha" (JESUS, 1961, p. 69). Em outro trecho desse diário, a autora afirma que se sente bem fora da favela, ela escreve: "A favela é um quarto de despejo e o meu sonho é residir numa casa de alvenaria" (JESUS, 1961, p. 91). Para a autora, a favela é um local inóspito, com péssimas condições de higiene, onde os da sala de visita jogam o lixo. É um ambiente abandonado e ignorado pelos políticos e pela elite.

Esse novo relato da vida da escritora inicia-se ainda na favela do Canindé, após Audálio Dantas ter conhecimento dos diários da escritora e propor-lhe publicá-los. As narrativas têm início com os preparativos para a assinatura do contrato para a publicação de Quarto de Despejo (2014a). Sendo assim, a autora registra o encontro com o pessoal da editora, os convites para participar de entrevistas nas rádios e nos jornais. Esses fatos vão, aos poucos, mudando a trajetória de Carolina de Jesus.

Preciso lavar as roupas, porque amanhã eu vou na televisão. Hoje eu estou alegre. Todo mundo olha-me nas ruas. Já estou habituada com a nova vida. Passei no bar do José, na rua Deocleciano e conversei com êle. Disse-lhe que não mais apareço porque não tenho tempo. Eu fui vista em todos os jornais (JESUS, 1961, p. 20).

Embora ainda morando na favela, Carolina de Jesus acostuma-se logo com os novos rumos que toma sua vida, de uma simples favelada, passa a ser reconhecida pelas pessoas nas ruas. Aparece em jornais, em programas de televisão, começa a colher os frutos do seu trabalho como escritora, proporcionando, desse modo, uma vida melhor aos filhos. 
Carolina de Jesus, ao receber a proposta de morar em um quarto na casa do senhor Antonio Soeiro Cabral, em Osasco, não esconde a alegria e a satisfação de sair da favela. Ela escreve: "Hoje é a última noite que eu vou dormir na favela. Avisei os filhos que vamos mudar amanhã. Ficaram alegres [...]. Estou contente. Até que enfim deixo este recanto maldito. Não vou incluir a saudade na minha bagagem” (JESUS, 1961, p. 44-45).

A escritora, depois de viver doze anos num quarto de despejo na favela do Canindé, tem a oportunidade de habitar a sala de visitas, com a qual tanto sonhou. Os sofrimentos e as privações pelas quais passou, durante os anos vividos na favela, deram origem ao seu livro e com os lucros da venda desse livro, no final de agosto de 1960, Carolina de Jesus, enfim, poderia ter uma vida melhor e proporcionar algum conforto aos seus filhos, longe da pobreza e do tumulto da favela.

A nova habitação da família Jesus “[...] era de um padrão compatível com as aspirações da classe média urbana de São Paulo” (MEIHY; LEVINE, 2015, p. 31). De acordo com os autores supracitados, a imprensa referir-se-ia à casa de Carolina de Jesus como barraco, contudo, para a família, era um verdadeiro palácio com sala, cozinha, jardim, água e energia elétrica.

A autora em questão tornou-se conhecida pelas pessoas: a catadora de papel que virou uma escritora admirada por muitos e criticada por outros. Sua rotina, após a publicação de Quarto de Despejo (2014a), resumia-se em autografar livros nas livrarias, conceder entrevistas para rádios e televisões, ser fotografada, visitar muitos lugares, sempre na companhia dos filhos. Apesar das atribulações, ela contentava-se com a situação, tendo em vista que seus esforços eram compensados, pois o seu livro era o mais vendido (JESUS, 1961).

Contudo, a convivência com pessoas de outro meio social, aos poucos, foi fazendo-a perceber que o preconceito e a discriminação permaneciam, embora ela não vivesse mais na favela. Muitas pessoas não aceitavam as verdades expostas por Carolina de Jesus em seu livro, acusavam-na de agitadora. Em um de seus relatos, ela cita que "O povo olha-me com curiosidade. Uns felicitam-me, outros me atacam, aludindo que o meu livro é agitador" (JESUS, 1961, p. 100). 
Apesar da realização do grande sonho de sair da favela e comprar uma casa, conforme Meihy e Levine (2015, p. 32, grifo dos autores), Carolina não tinha sossego em sua nova morada, eram visitantes, curiosos, pessoas pedindo dinheiro, jornalistas, fotógrafos, a vizinhança “[...] os rejeitavam, curiosos os espiavam como avis rara a todas as horas".

Carolina de Jesus, ao conviver com pessoas ricas, percebe também que os que habitam as salas de visita são ambiciosos, gananciosos, oportunistas e muitos só queriam se aproveitar do dinheiro dela. Ela afirma: "Quando não tinha dinheiro não tinha sossego com a fome a envolver-me no seu manto negro. Agora tenho dinheiro e não tenho sossego com os oportunistas, os piratas que querem aproveitar-se da minha situação" (JESUS, 1961, p. 102).

Com o passar dos dias, a escritora ia ficando descontente; o burburinho da cidade, a falta de tempo e de calma privavam-na de escrever. Na favela, durante o dia ela catava papel, mas à noite podia escrever durante horas, até que dormisse (MEIHY; LEVINE, 2015).

A casa de alvenaria trouxe muitas alegrias para Carolina de Jesus, todavia o convívio com as classes rica e média comprovou o que a escritora pensava sobre a 'Dona Elite', que ignora a realidade dos que vivem nos quartos de despejos e "[...] encara o problema da favela com vergonha" (JESUS, 1961, p. 180). Esses escritos retratam a postura das pessoas que vivem nas salas de visitas e que menosprezam os que habitam os quartos de despejos das favelas.

\section{Diário de Bitita: as lembranças de Carolina Maria de Jesus}

Em ordem cronológica de publicação, Diário de Bitita (2014b) é o último diário da escritora a ser lançado. Conforme Fernandez (2019), Carolina de Jesus entregou os manuscritos que deram origem ao referido diário a uma brasileira, que posteriormente foram divulgados em uma versão francesa, Journal de Bitita, em 1982. Somente em 1986 a editora Nova Fronteira comprou os direitos autorais e o lançou com o título atual (MIRANDA, 2013). 
As narrativas desse diário são memorialísticas, uma vez que a escritora relembra o período de sua infância e de sua adolescência. De família humilde, desprovida de recursos, Bitita vivia em uma casa demasiado pobre, recoberta de sapê, com parede de adobe e chão batido e sua mãe trabalhava como empregada para famílias brancas. Sempre curiosa, muito inteligente e até mesmo impertinente, a menina questionava tudo o que não entendia ou o que a incomodava.

Nesse relato, Carolina de Jesus lança mão de vários temas, contudo, observamos que a pobreza, a fome, o preconceito e o racismo são marcas fortes nas narrativas da autora. Partindo desse pressuposto, focaremos nosso discurso em torno desses temas, todavia, não pretendemos reduzir a produção literária da autora a temas sociais ou raciais, mas entendemos que quando discorremos sobre a vida e obra de uma mulher, negra, pobre, semianalfabeta e favelada, a abordagem desses assuntos faz-se urgente e necessária.

Em Diário de Bitita (2014b), a escritora retrata a difícil situação dos negros, grande parte analfabeta. Quando eram jovens, trabalhavam bastante para sobreviver, depois que atingiam a velhice, tinham que pedir esmolas no campo, pois somente "os mendigos oficializados” pela câmara podiam pedir esmolas na cidade (JESUS, 2014b, p.31).

As negras, ainda meninas, eram assediadas, “[...] eram brutalizadas pelos filhos do senhor Pereira, Moreira, Oliveira, e outros porqueiras [...]”, muitas engravidavam e tinham que cuidar sozinhas dos filhos, visto que perderiam o emprego se revelassem quem era o pai da criança. O filho do patrão, depois de abusar das meninas pobres e negras, casava-se com uma moça rica (JESUS, 2014b, p. 39).

Bitita, embora sendo criança, percebia com clareza que os pobres e negros tinham uma existência sofrida. Embora já fossem livres, os negros eram privados de muitos direitos essenciais, como alimentação, trabalho e moradia, além do preconceito explícito ao qual eram expostos. Para Souza (2017), a abolição da escravatura não livrou os negros do racismo e nem do abandono em guetos e favelas. Como afirma Carolina de Jesus (2014a), em Quarto de Despejo, o negro precisa lutar contra a escravatura atual que é a fome. 
Outro direito essencial negado aos negros, principalmente para as mulheres negras, era a instrução formal. A autora mesmo só conseguiu estudar pelo período de dois anos, por intermédio de uma senhora para quem sua mãe trabalhava. Com dificuldades financeiras, ela e a família tiverem que deixar a cidade e ela não pôde mais estudar.

Desse modo, a autora afirma que "No ano de 1925, as escolas admitiam alunas negras. Mas quando as alunas negras voltavam das escolas, estavam chorando. Dizendo que não queriam voltar à escola porque os brancos falavam que os negros eram fedidos" (JESUS, 2014b, p. 42).

O racismo e o preconceito são outros pontos retratados por Carolina de Jesus. Em vários trechos de Diário de Bitita (2014b), ela enfatiza a diferenciação entre os brancos e os negros. Ela escreve que quando havia algum conflito, os negros é que eram presos, mesmo que só estivessem observando, pois os brancos não podiam ser presos “[...] uma pele branca era um escudo, um salvo-conduto" (JESUS, 2014b, p.54).

O branco europeu, acreditando em sua superioridade, fez o negro crer que era uma raça inferior. Com base no preconceito, na discriminação e num discurso de exclusão, o homem branco segrega o negro, colocando-o numa situação de submisso. Essa visão eurocêntrica induzia os negros a crerem que para usufruir de seus direitos deveriam ter uma existência branca, baseada na cultura europeia.

Desse modo, Munanga (2019) defende que os europeus, convencidos de sua superioridade, desprezavam os negros. A falta de conhecimento sobre a história dos negros, as diferenças étnico-culturais “[...] predispuseram o espírito do europeu a desfigurar completamente a personalidade moral do negro e suas aptidões intelectuais. Negro torna-se, então, sinônimo de ser primitivo, inferior, dotado de uma mentalidade pré-lógica" (MUNANGA, 2019, p. 24).

Tomamos ciência de que Bitita não viveu a escravidão, mas conhecia de perto os horrores de quem a viveu através dos relatos feito pelo seu avô e também por meio dos livros que lia sobre esse tema. Seu avô falava sobre o sofrimento dos negros, da história de Zumbi dos Palmares, do sonho de liberdade e dos “[...] pretos que morriam com vinte 
e cinco anos: de tristeza, porque ficavam com nojo de serem vendidos" (JESUS, 2014b, $61)$.

O sofrimento dos negros não teve fim com a abolição da escravatura, pois os negros continuam marginalizados, sofrendo o racismo velado. A ideologia eurocêntrica, ao reforçar os estereótipos de brancura, cria mecanismos de exclusão e impulsiona o racismo, ao ponto de o próprio negro negar suas características.

Bitita vivenciou experiências desse tipo na rua, na escola quando era chamada de negrinha fedida e até mesmo no seio da família, pois a garotinha sentia-se preterida pela mãe que, segundo ela, gostava mais de seu irmão, que era mulato, que dela, que era negra.

A luta diária de Carolina de Jesus e de sua família pela sobrevivência obrigou-as a viver em constante movimento entre a cidade e o campo e entre outros estados, culminando com a vinda da escritora para São Paulo, dando início assim, à saga da mulher negra que morava num quarto de despejo e, escrevendo sobre a favela, tornouse conhecida mundialmente, concretizando, desse modo, o sonho de comprar sua casa de alvenaria; contudo, morreu na pobreza.

\section{Considerações finais}

Carolina de Jesus traz, em seus escritos, o retrato da situação de precariedade e pobreza vivida, não só por ela, mas por muitos outros negros e pobres, que sofriam e ainda sofrem discriminação e preconceito por questões de raça ou de classe social. Diante das leituras e análises empreendidas, percebemos a identidade de Carolina impregnada em suas obras, especialmente, em seus diários.

Por meio de seus diários, podemos conhecer a trajetória da escritora negra, pobre e semianalfabeta que ganhou destaque ao retratar a realidade da favela, uma realidade ignorada por grande parte da população brasileira. Em Quarto de Despejo (2014a), deparamo-nos com a mulher Carolina de Jesus, habitante da favela do Canindé, mãe solteira de três filhos. Nesse cenário, a fome torna-se uma personagem que ganha cores 
e desumaniza as pessoas, obrigando-as a sobreviveram em quartos de despejos, alimentando-se dos restos lançados no lixo.

Nesse diário, a denúncia social ganha força, tendo em vista que os relatos da escritora mostram uma realidade até então ignorada pelos que viviam nas salas de visita; como ela mesma afirma, a favela é o quintal, onde os ricos jogam o lixo.

Em Casa de Alvenaria (1961) vemos uma Carolina de Jesus em meio aos preparativos para a assinatura do contrato para a publicação do seu primeiro diário. Entre idas e vindas, entrevistas e participação em eventos, a vida da escritora vai sofrendo mudanças significativas, e ela vê a concretização do grande sonho de sair do quarto de despejo da favela para viver na sala de visitas de uma casa de alvenaria.

Já em Diário de Bitita (2014b), tomamos conhecimento dos fatos marcantes da infância e da adolescência da escritora. Inteligente e inquieta não compreendia por qual razão os pobres e os pretos sofriam tanto e nem o motivo de haver diferenciação em relação a cor da pele das pessoas. Ao se dar conta dessas diferenças, em alguns momentos, Bitita, influenciada por uma ideologia eurocêntrica, desejava ter a pele branca para poder usufruir dos privilégios destinados aos brancos.

Desse modo, constatamos que os diários da escritora apresentam a trajetória da esperta menina Bitita, que desde a infância sempre batalhou para fugir da fome e do preconceito. Ao mudar-se para São Paulo, em busca de uma vida melhor, teve suas expectativas frustradas tendo em vista que a metrópole hospitaleira não acomodava todos os migrantes e muitos deles, como ela, tiveram que ir viver nos quartos de despejos das favelas e catar papel para sobreviver.

Embora vivendo na sala de visitas, ela percebe que muitas pessoas são oportunistas e só querem se aproveitar do dinheiro dela. A constatação de que a elite não se interessa pelos problemas da favela causa decepção à escritora, assim como a confirmação de que a mudança de ambiente não muda o preconceito e a discriminação, com os quais são tratados os negros e os pobres.

\section{Referências}


BANDEIRA, Manuel. $O$ bicho. Rio de Janeiro, 1947. Disponível em: https://www.escritas.org/pt/t/4828/o-bicho. Acesso em: 20 abr. 2020.

BUTLER, Judith. Relatar a si mesmo: crítica da violência ética. Tradução: Rogério

Bettoni. -1 ed. - Belo Horizonte: Autêntica Editora, 2015.

FERNANDEZ, Raffaella. A poética de resíduos de Carolina Maria de Jesus. São Paulo: Aetia Editoral, 2019.

FOUCAULT, Michel. A escrita de si. In: O que é um autor? Lisboa: Passagens, 1992, pp. 129-16o.

JOVIANO, Lúcia Helena da Silva. Diário e escrita de si: 'Minha vida de Menina' no contexto da discursividade Moderna. Darandina Revisteletrônica. Anais do Simpósio Internacional Literatura, Crítica, Cultura V: Literatura e Política. Faculdade de Letras da Universidade Federal de Juiz de Fora, 2011. Disponível em: http://www.ufjf.br/ darandina/files/2011/o8/Diário-e-escrita-de-si-Minha-vida-de-Menina-no-contexto-dadiscursividade-Moderna.pdf. Acesso em: 12 ago. 2019.

JESUS, Carolina Maria de. Quarto de despejo: diário de uma favelada. 10 ed. São Paulo: Ática, 2014a.

. Diário de Bitita. São Paulo: SESI - SP editora, 2014b.

. Casa de alvenaria: diário de uma ex-favelada. São Paulo: Paulo Azevedo, 1961.

MEIHY, José Carlos Sebe Bom; LEVINE, Robert M. Cinderela Negra: a saga de Carolina Maria de Jesus. 2 ed. Sacramento MG: Editora Bertolucci, 2015.

MIRANDA, Fernanda Rodrigues de. Os caminhos literários de Carolina Maria de Jesus: Experiência marginal e construção estética. São Paulo. 2013. 153 f. Dissertação (Mestrado) - Faculdade de Filosofia, Letras e Ciências Humanas da Universidade de São Paulo, São Paulo, 2013.

MUNANGA, Kabengele. Negritude: usos e sentidos. 2 ed. São Paulo: Ática, 1988. Disponível em: https://www.passeidireto.com/lista/68058407-be/arquivo/19197106munanga-kabengele-negritude-usos-e-sentidos. Acesso em: 15 ago. 2019.

PERPÉTUA, Elzira Divina. A vida escrita de Carolina Maria de Jesus. Belo Horizonte: Nandyala, 2014. 
PERROT, Michele. Minha história das mulheres. Tradução de Angela M. S. Côrrea. São Paulo: Contexto, 2007.

SOUZA, Élio Ferreira de. Poesia negra: Solano Trindade e Langston Hughes. - 1 ed. Curitiba: Appris, 2017.

Recebido em 20/04/2020. Aprovado em 22/06/2020. 